\title{
Chikungunya virus infection with severe neurologic manifestations: report of four fatal cases
}

\author{
Priscilla Karen de Oliveira Sá ${ }^{[1]}$, Michaela de Miranda Nunes ${ }^{[1]}$, Ingrid Ramalho Leite ${ }^{[1]}$, \\ Maria das Graças Loureiro das Chagas Campelo ${ }^{[1]}$, Cláudia Ferreira Ribeiro Leão ${ }^{[1]}$, \\ Joelma Rodrigues de Souza $a^{[2],[3]}$, Lúcio Roberto Castellano ${ }^{[2]}$ \\ and Ana Isabel Vieira Fernandes ${ }^{[2],[4]}$
}

\begin{abstract}
[1]. Hospital Regional de Emergência e Trauma Dom Luiz Gonzaga Fernandes, Campina Grande, PB, Brasil. [2]. Grupo de Estudos e Pesquisas em Imunologia Humana, Escola Técnica de Saúde, Universidade Federal da Paraíba, João Pessoa, PB, Brasil. [3]. Departamento de Fisiologia e Patologia, Centro de Ciências da Saúde, Universidade Federal da Paraíba, João Pessoa, PB, Brasil. [4]. Serviço de Doenças Infecciosas e Parasitárias, Hospital Universitário Lauro Wanderley, Universidade Federal da Paraíba, João Pessoa, PB, Brasil.
\end{abstract}

\begin{abstract}
Here, we present four patients with confirmed Chikungunya virus infection showing atypical neurologic manifestations and death. This case series includes patients ranging in age from five to 92 years, with or without comorbidities. This report is important, as very few cases in the literature reporting death due to atypical Chikungunya virus infection are available.
\end{abstract}

Keywords: Chikungunya fever. Neurologic manifestations. Death.

\section{INTRODUCTION}

Chikungunya fever is transmitted to humans by mosquitoes of the genus Aedes and is caused by the chikungunya virus (CHIKV). CHIKV was first isolated in 1952 in Tanzania and was responsible for major epidemics in Asia in the 1950s and 1960s. CHIKV reemerged in 2005 and is currently found in at least one country of each continent ${ }^{1}$.

In Brazil, the first CHIKV case was reported in $2010^{2}$. Autochthonous transmission was detected in September of $2014^{3}$. In 2016, through the $13^{\text {th }}$ epidemiological week, 39,017 suspected cases were notified, and 6,159 were confirmed. The Northeastern Region showed the highest incidence rate (56 cases/100,000 inhabitants) with 12 deaths ${ }^{4}$.

Infection by CHIKV is characterized by an abrupt onset of fever and moderate to severe arthralgia, myalgia, headache, rash, fatigue, and nausea ${ }^{5}$. Atypical manifestations have been described, such as cardiovascular; ocular; gastrointestinal; renal; and neurological impairments, including altered level of consciousness, alterations in cranial nerves, seizures, psychosis, hemi/paraparesis, paraplegia, involuntary movements, and Guillain-Barré syndrome (GBS) ${ }^{6,7}$.

Corresponding author: Profa. Ana Isabel Vieira Fernandes. e-mail: anaisabelvf@gmail.com

Received 14 September 2016

Accepted 20 December 2016
Here, four cases of severe CHIKV infection are described, with ages varying between 5- and 92-years-old, both sexes, with and without comorbidities. All of the cases experienced fast and fatal evolution.

\section{CASE REPORTS}

The four patients were admitted to the Hospital Regional de Emergência e Trauma Dom Luiz Gonzaga Fernandes at Campina Grande, Paraiba, Brazil. Patient 1 and Patient 3 were from Campina Grande ( $\left.7^{\circ} 13^{\prime} 20.4^{\prime \prime} \mathrm{S} 35^{\circ} 52^{\prime} 48.1^{\prime \prime} \mathrm{W}\right)$ located in the Agreste region of Paraíba State, $112 \mathrm{~km}$ from the capital city of João Pessoa. Patient 2 and Patient 4 were from Monteiro $\left(7^{\circ} 53^{\prime} 30.1^{\prime \prime S} 37^{\circ} 07^{\prime} 34.6^{\prime \prime} \mathrm{W}\right)$, a city with 33,039 inhabitants located in the Borborema region of Paraíba State, $300 \mathrm{~km}$ from João Pessoa and 170km from Campina Grande. Patients 2 and 4 were admitted to a local Health Service in the municipality of Monteiro and then moved to the hospital at Campina Grande.

Patient 1. A $<5$-year-old child, previously healthy, was admitted on January 12, 2016. He presented with a 1-day history of fever, intense myalgia, arthralgia, headache, and vomiting; he experienced two tonic-clonic seizures 7 hours prior to admission and cardiorespiratory arrest (CRA) 4 hours prior to admission. He was brought to our service on mechanical ventilation, with a Glasgow Coma Scale (GCS) score of 3. During examination, the patient was afebrile, dehydrated $(++/ 4+)$, showed unaltered cardiac and respiratory auscultations, and had a flaccid abdomen; he showed no signs of visceromegaly or bleeding, but presented with deep areflexia (negative corneal-palpebral, oculomotor, and cough reflexes). Cranial computed tomography 
(CT) scan showed diffuse cerebral edema. Lumbar puncture was contraindicated. Intravenous antibiotic therapy was started. The patient developed leukopenia by the third day of hospitalization. On the sixth day, he showed a diffuse rash on his trunk, abdomen, and limbs. At this time, serological tests for CHIKV [positive Mac-enzyme-linked immunosorbent assay (ELISA) immunoglobulin M (IgM)] and dengue [negative nonstructural protein 1 (NS1)] were performed. Blood, urine, and tracheal secretion cultures were negative. Death was declared on February 4, 2016.

Patient 2. A 51-year-old female farmer with noninsulindependent diabetes was admitted on February 9, 2016. She complained of sudden lumbosacral pain in the previous 2 days, followed by loss of bowel control; 15-day history of fever, arthralgia, and skin rash also reported. At admission, she was conscious, oriented, and breathing spontaneously, but also sleepy and febrile. She presented with tetraparesis and stiff neck, without signs of joint inflammation. Cardiac and respiratory auscultation was unaltered and her blood pressure and blood glucose test (HGT) were normal. A complete blood count (CBC) and cerebrospinal fluid (CSF) analysis were obtained by lumbar puncture (Table 1). An anti-human immunodeficiency virus (HIV) ELISA was negative, as were blood and CSF cultures. A CT scan of both the thoracic and lumbosacral spine was performed on February 10, 2016, which showed a slight thickening of the thoracic segment of the spinal cord. Broad spectrum antibiotic therapy was started. In serum samples, IgM
(Mac-Elisa) was negative for dengue and positive for CHIKV. She developed lethargy and respiratory difficulties, and oxygen therapy with a reservoir bag was started. The patient did not respond well to supportive care measures and, 38 hours after hospital admission, she went into CRA and died.

Patient 3. A 65-year-old male farmer with history of alcohol abuse and diabetes was admitted to the hospital on January 22, 2016. He presented with a decreased level of consciousness and reported seizures 1.5 hours before arriving at the hospital. Family members informed hospital staff that the patient had fever, joint pain, and exanthema 10 days prior. Examination on admission revealed an absence of fever, normal blood pressure levels, elevated capillary blood glucose (CBG), normal urine output, GCS score of 9 , and respiratory difficulties. The patient had normal cardiac and respiratory auscultations, a flaccid abdomen, and no visceromegaly. Petechiae were identified on the lower legs as well as periorbital ecchymosis. Pedal pulses were bilaterally absent. He was placed on mechanical ventilation, then intravenous antibiotic therapy with acyclovir was started. The blood and urine cultures collected were negative for bacteria, dengue virus, and HIV; and positive for CHIKV (IgM+). Cranial CT scan showed bilateral frontal hypoattenuation. Complete CSF analysis was performed (Table 1). The patient died 27 hours after hospital admission.

Patient 4. A 92-year-old woman was admitted to the hospital on March 13, 2016 with 9-day history of fever, arthralgia, and exanthema; she also described episodes of vomiting and

TABLE 1

Clinical and laboratory aspects of CHIKV infections.

\begin{tabular}{|c|c|c|c|c|c|c|c|c|c|c|c|}
\hline Cases & Sex & $\begin{array}{c}\text { Age } \\
\text { (years) }\end{array}$ & Comorbidity & Leukocytes & Lymphocytes & $\begin{array}{c}\text { Ionogram } \\
(\mathrm{mEq} / \mathrm{L})\end{array}$ & Urea & $\begin{array}{c}\text { Creatinine } \\
\text { (mg/dL) }\end{array}$ & CSF & CT Scan & Serology \\
\hline Patient 1 & M & 5 & No & 5,700 & 456 & $\begin{array}{l}\text { Na } 157 \\
\text { K } 3.7\end{array}$ & 20 & 1 & Not analyzed & $\begin{array}{l}\text { Diffuse cerebral } \\
\text { edema }\end{array}$ & $\begin{array}{c}\operatorname{IgM}+ \\
\text { Chikungunya; } \\
\text { NS1 negative } \\
\text { dengue. }\end{array}$ \\
\hline Patient 2 & $\mathrm{~F}$ & 51 & $\mathrm{DM}$ & $\begin{array}{c}20,100 \\
(16 \% \text { band } \\
\text { cells })\end{array}$ & 1,800 & $\begin{array}{l}\mathrm{Na} 151 \\
\text { K } 3.5\end{array}$ & 92 & 0.9 & $\begin{array}{l}\text { Leukocytes: } \\
113(90 \% \\
\text { lymphocytes) } \\
\text { Glucose: } \\
269 \mathrm{mg} / \mathrm{dL} \\
\text { Proteins: } 291 \\
\mathrm{mg} / \mathrm{dL}\end{array}$ & $\begin{array}{l}\text { Slight thickening of } \\
\text { thoracic segment of } \\
\text { the spinal cord and } \\
\text { small collections/ } \\
\text { abscesses in the right } \\
\text { iliopsoas muscles, } \\
\text { measuring } 3.0 \times 2.0 \\
\mathrm{~cm} \text { in its major axis. }\end{array}$ & $\begin{array}{c}\operatorname{IgM}+ \\
\text { Chikungunya; } \\
\text { IgM negative } \\
\text { dengue. }\end{array}$ \\
\hline Patient 3 & M & 65 & $\begin{array}{l}\text { DM and } \\
\text { alcoholism }\end{array}$ & $\begin{array}{c}12,100 \\
(20 \% \text { band } \\
\text { cells })\end{array}$ & 726 & $\begin{array}{l}\mathrm{Na} 154 \\
\mathrm{~K} 3.1\end{array}$ & 134 & 2.9 & $\begin{array}{l}\text { Leukocytes: } \\
4 \text { Glucose: } \\
327 \mathrm{mg} / \mathrm{dL} \\
\text { Proteins: } \\
57.5 \mathrm{mg} / \mathrm{dL}\end{array}$ & $\begin{array}{l}\text { Bilateral frontal } \\
\text { hypoattenuation }\end{array}$ & $\begin{array}{c}\operatorname{IgM}+ \\
\text { Chikungunya; } \\
\text { IgM negative } \\
\text { dengue. }\end{array}$ \\
\hline Patient 4 & $\mathrm{Fe}$ & 92 & No & $\begin{array}{c}15,900 \\
(5 \% \text { band cells })\end{array}$ & 954 & $\begin{array}{l}\mathrm{Na} 123 \\
\mathrm{~K} 4.1\end{array}$ & 27 & 1.1 & Not analyzed & No acute alterations & $\begin{array}{c}\operatorname{IgM}+ \\
\text { Chikungunya; } \\
\text { IgM negative } \\
\text { dengue. }\end{array}$ \\
\hline
\end{tabular}

CHIKV: Chikungunya virus; CSF: cerebrospinal fluid; CT: computed tomography; M: male; F: female; DM: diabetes mellitus; IgM: immunoglobulin M; NS1: non-structural protein 1 . 
diarrhea in the previous 3 days. She developed a decreased level of consciousness and was brought to our service already on mechanical ventilation. She demonstrated involuntary movements in lower limbs, but had no significant alterations in cardiac and respiratory auscultations, or signs of bleeding. A computed tomography scan showed no acute alterations. The patient evolved with no neurological improvement, dying 10 days after her admission to the hospital.

Laboratory analyses such as hematological, biochemical, and microbiological (bacteria and fungi) as well as imaging exams were performed at the Hospital Regional de Emergência e Trauma Dom Luiz Gonzaga Fernandes at Campina Grande. Specific serology for chikungunya, dengue, HIV, and hepatitis viruses were performed at Paraíba State Central Laboratory [Laboratório Central de Saúde Pública da Paraíba (LACEN$\mathrm{PB})]$, the public reference laboratory for diagnosis of infectious diseases and member of a National Network for certified diagnostic laboratories under the auspices of the Brazilian Ministry of Health. All four patients yielded negative results for dengue, HIV, and hepatitis serologies. Microbiological cultures of the CSF, urine, and blood were also negative.

\section{Ethical considerations}

This work was part of a larger project on Arbovirosis approved by UFPB Ethical Committee on Human Research (protocol \#032/2009/CEP/HULW/UFPB). Written informed consent was obtained from the patient for publication of this case report.

\section{DISCUSSION}

Infection by CHIKV has been described to be similar to dengue fever. However, some atypical cases were reported with a mortality rate of about $10 \%$, and independent risk factors have been described ${ }^{8,9}$. Neurological complications have been described since as early as 1960 and still need special attention. Twelve percent of patients from the Reunion Island outbreak presented with an altered level of consciousness, cranial nerve deficits, seizures, and other neurological manifestations ${ }^{7}$.

The cases reported here represent extremes with regard to age and neurological involvement that rapidly evolved and resulted in death. All of the cases occurred in the months of February and March of 2016, which is coincidently the same period that the majority of deaths associated with CHIKV occurred in the Brazilian Northeastern Region ${ }^{4}$.

In the first case, a previously healthy boy presented with initial symptoms compatible with CHIKV, which evolved with two generalized tonic convulsive crises and a diminished level of consciousness. Rash was observed only on the sixth day of disease onset, suggestive of arbovirus serology. In a study performed in India, 7 of 66 children presenting with neurological alterations were positive for CHIKV and had seizure episodes, whereas in 4 of them the epileptic status persisted for $>30$ minutes and rash only appeared after the third day of febrile status ${ }^{10}$.

Another severe form was observed in patient 2, a 51-yearold woman with diabetes whose symptoms were neurological alterations compatible with GBS as well as myositis associated with abscesses. During the 2005 chikungunya outbreak in India, incapacitating polyarthralgia and myalgia were reported in $97.7 \%$ of the cases. From this observation, biopsies taken from skeletal muscles demonstrated the presence of viral antigens inside tissue progenitor cells, which might contribute to the pathophysiology of the disease ${ }^{11}$.

The third patient presented with risk factors consistent with other cases of disease severity, such as alcoholism and age $>65$ years. In this patient, the CT revealed bilateral frontal hypoattenuation, whereas abnormal cellularity and elevated protein levels were detected in a CSF analysis, consistent with a previous report in the literature ${ }^{9}$.

The fourth patient, an elderly woman, presented with vomiting and diarrhea and evolved to a decreased level of consciousness and uncontrollable movements of the inferior members, despite a normal CT scan. Considering the laboratory analysis, the patient presented with lower sodium levels, which is consistent with $12 \%$ of neurologically-altered chikungunya fever cases previously described ${ }^{9}$.

It is notable that all four patients reported here were considered positive CHIKV cases by Health Authorities. They all also came from areas with a massive and active viral circulation at the time they were admitted to the hospital. As stated by the Pan American Health Organization (PAHO) any suspected case of CHIKV infection should be confirmed when at least one of the tests returns positive, as follows: anti-CHIKV IgM positivity (collected during acute or convalescence phase); a 4-fold increase in antibody titer demonstrating seroconversion preferably after 10-14 days of acute phase start or after 1445 days after symptoms start; viral isolation (acute phase); polymerase chain reaction; or plaque reduction neutralization testing (PRNT) in a single serum sample ${ }^{12}$. In our study, the only confirmatory test for CHIKV infection available at that time was the IgM-based serology, which is compliant with PAHO recommendations.

A limitation of this study is the lack of viral isolation or molecular diagnosis of CHIKV. Although the gold standard would be the molecular virology studies, one must consider the fact that detection of specific CHIKV IgM is extremely acceptable as an international standard for these cases as stated by PAHO. Moreover, similar studies found in the literature describing CHIKV outbreaks at Reunion Island adopted the serologic test for confirmation of $>91.75 \%{ }^{13}$ and $43.9 \%{ }^{14}$ of their cases.

Neurologic manifestations are life-threatening complications in CHIKV-infected patients, even in those without any comorbidity. Considering the lack of biomarkers for CHIKV fever progression and the emerging status of CHIKV infection, the cases presented here serve as an alert for clinicians and health authorities to dedicate more attention to children, elders, and immunocompromised patients, who are more likely to present with neurologic manifestations and a fatal outcome in CHIKV infection. 


\section{Acknowledgements}

The authors are thankful to the families of the patients enrolled in this study.

\section{Conflict of interest}

The authors declare there is no conflict of interest.

\section{REFERENCES}

1. Lahariya C, Pradhan SK. Emergence of chikungunya virus in Indian subcontinent after 32 years: a review. J Vector Borne Dis. 2006;43(4):151-60.

2. de Albuquerque IGC, Marandino R, Mendonça AP, Nogueira RMR, Vasconcelos PFC, Guerra LR, et al. Chikungunya virus infection: report of the first case diagnosed in Rio de Janeiro, Brazil. Rev Soc Bras Med Trop. 2012;45(1):128-9.

3. Honorio NA, Camara DC, Calvet GA, Brasil P. Chikungunya: an arbovirus infection in the process of establishment and expansion in Brazil. Cad Saúde Pública. 2015;31(5):906-8.

4. Secretaria de Vigilância em Saúde. Boletim Epidemiológico. Monitoramento dos casos de dengue, febre de chikungunya e febre pelo vírus Zika até a Semana Epidemiológica 13, 2016. Ministério da Saúde. 2016;47(18):1-10. [Internet]. 2016 [cited 01/08/2016]. Available from: http://portalsaude.saude.gov.br/index. php/o-ministerio/principal/leia-mais-o-ministerio/197-secretariasvs/11955-boletins-epidemiologicos-arquivos.

5. Rajapakse S, Rodrigo C, Rajapakse A. Atypical manifestations of chikungunya infection. Trans R Soc Trop Med Hyg. 2010;104(2):89-96.

6. Ludlow M, Kortekaas J, Herden C, Hoffmann B, Tappe D, Trebst $\mathrm{C}$, et al. Neurotropic virus infections as the cause of immediate and delayed neuropathology. Acta Neuropathol. 2015;131(2):159-84.
7. Tandale BV, Sathe PS, Arankalle VA, Wadia RS, Kulkarni R, Shah $\mathrm{SV}$, et al. Systemic involvements and fatalities during Chikungunya epidemic in India, 2006. J Clin Virol. 2009;46(2):145-9.

8. Lemant J, Boisson V, Winer A, Thibault L, Andre H, Tixier F, et al. Serious acute chikungunya virus infection requiring intensive care during the Reunion Island outbreak in 2005-2006. Crit Care Med. 2008;36(9):2536-41.

9. Economopoulou A, Dominguez M, Helynck B, Sissoko D, Wichmann O, Quenel $\mathrm{P}$, et al. Atypical Chikungunya virus infections: clinical manifestations, mortality and risk factors for severe disease during the 2005-2006 outbreak on Reunion. Epidemiol Infect. 2009;137(4):534-41.

10. Lewthwaite P, Vasanthapuram R, Osborne JC, Begum A, Plank JLM, Shankar MV, et al. Chikungunya virus and central nervous system infections in children, India. Emerg Infect Dis. 2009;15(2):329-31.

11. Ozden S, Huerre M, Riviere JP, Coffey LL, Afonso PV, Mouly V, et al. Human muscle satellite cells as targets of Chikungunya virus infection. PloS One. 2007;2(6):e527.

12. Pan American Health Organization. Preparedness and Response for Chikungunya Virus Introduction in the Americas. Washington, DC: PAHO; 2011.

13. Renault P, Solet J-L, Sissoko D, Balleydier E, Larrieu S, Filleul L, et al. A major epidemic of Chikungunya vrus infection on Réunion Island, France, 2005-2006. Am J Trop Med Hyg. 2007;77(4): 727-31.

14. Borgherini G, Poubeau P, Staikowsky F, Lory M, Moullec NL, Becquart JP, et al. Outbreak of Chikungunya on Reunion Island: early clinical and laboratory features in 157 adult patients. Clin Infect Dis. 2007;44(11):1401-7. 